\title{
Bimbingan Keagamaan dan Dampaknya terhadap Sikap Keagaamaan Mualaf di Panti Asuhan al-Falah
}

\author{
Napri \\ Universitas Muhammadiyah Sumatera Barat \\ naprispdi123@gmail.com
}

\begin{abstract}
Mualaf is classified as a person who needs religious guidance, on the basis of these needs Al-Falah Koto Tangah orphanage has a program oriented towards increasing Mualaf knowledge of Islamic teachings. The results of this religious guidance should be practiced by every Mualaf. Therefore, this study aims to describe how the impact of religious guidance on religious attitudes Mualaf. The research was conducted with a qualitative approach, data sources included orphanage caregivers and Mualaf in al-Falah orphanage. Data is collected through observation, interview and documentation studies, all data is analyzed through data reduction, classification, presentation and interpretation and withdrawal of conclusions. The results of the study were Mualaf in orphanages getting religious guidance in aspects of prayer, reading the Qur'an, practicing sunnah worship and morals. The existence of various forms of guidance, Mualaf in al-Falah orphanage is able and memorizes the readings and movements of prayer, has the ability to read the Qur'an, know and have good morals.
\end{abstract}

Keywords: Mualaf; religious guidance; prayer; Reading the Qur'an

\section{Abstrak}

Mualaf tergolong orang yang membutuhkan bimbingan keagamaan, atas dasar kebutuhan tersebut panti asuhan al-Falah Koto Tangah memiliki program yang berorientasi pada peningkatan pengetahuan Mualaf terhadap ajaran Islam. Hasil bimbingan keagamaan ini semestinya diamalkan oleh setiap Mualaf. Oleh karenanya, penelitian ini bertujuan untuk mendeskripsikan bagaimana dampak bimbingan keagamaan terhadap sikap beragama Mualaf. Penelitian dilakukan dengan pendekatan kualitatif, sumber data meliputi pengasuh panti dan Mualaf yang ada di panti asuhan al-Falah. Data dikumpulkan melalui observasi, wawancara dan studi dokumentasi, semua data dianalisis melalui reduksi data, klasifikasi, penyajian dan interpretasi dan penarikan kesimpulan. Hasil penelitian adalah Mualaf di panti asuhan mendapatkan bimbingan keagamaan dalam aspek ibadah salat, membaca Alquran, pengamalan ibadah sunnah serta akhlak. Keberadaan berbagai bentuk bimbingan tersebut, Mualaf di panti asuhan al-Falah mampu dan hafal bacaan dan gerakan salat, memiliki kemampuan membaca Alquran, mengetahui dan memiliki akhlak yang baik.

Kata Kunci: Mualaf; Bimbingan Agama; Salat; Membaca Alquran

Article Info

Recived: 01/10/2021. Accepted: 11/12/2021. Publish: 16/12/2021. 


\section{Pendahuluan}

Dalam Islam kalau ada orang yang beragama lain masuk Islam disebut Mualaf atau orang yang baru masuk Islam. Syariat Islam mengajarkan kepada umat Islam untuk memperlakukan Mualaf dengan santun ${ }^{1}$, membujuk hatinya agar tetap istikamah dengan agama yang diyakininya ${ }^{2}$. Kewajiban mengayomi Mualaf ini seiring dengan ajaran Islam yang mengelompokkan Mualaf sebagai bagian dari orang yang berhak untuk menerima zakat. Namun kenyataanya dalam masyarakat golongan Mualaf ini masih terabaikan dalam pembinaannya secara maksimal dan berkesinambungan, bahkan terkesan Mualaf belum mendapat simpati dari kaum muslimin dengan baik, padahal persoalan Mualaf ini sangat kompleks dan dapat menjadi beban berkepanjangan ${ }^{3}$, apabila tidak ada solusi yang tepat dalam menuntaskan setiap persoalan yang dihadapi mualaf maka hal ini akan menjadi dosa bagi setiap muslim. Hal ini sesuai dengan yang disampaikan oleh Pembina panti al-Falah "Bagi seorang Mualaf (baru masuk Islam), bukanlah hal yang mudah untuk dihadapi atau dijalani, apalagi bagi seorang anak yang masih membutuhkan perhatian dan kasih sayang dari orang tua, sangat berat sekali bagi mereka, kepada siapa mereka mengadukan masalahnya, terutama yang masih berlaianan agama dengan kelurganya, akan semakin membuat anak itu tertekan persaan demikian juga dengan pergaulannya yang sangat terbatas dibandingkan dengan sebelum dia menjadi Mualaf. Lebih lanjut dikatakan bahwa kedaan mereka itu yang kurang dipahami orang lain atau orang muslim lainnya, maka kami di Panti Asuhan al-Falah ini mencoba untuk memberikan bantuan kepada Mualaf yang dibina baik berupa kebutuhan harian maupun bimbingan keagamaan walaupun belum maksimal.

Dari hasil wawancara di atas dapat dipahami bahwa apabila sesorang baru masuk Islam, bukanlah tanpa menimbulkan masalah baru terutama bagi Mualaf itu sendiri, sepintas lalu orang menyaksikan Mualaf itu mendapat keberuntungan yang besar karena mendapat hidayah dari Allah dengan masuk Islam, tapi kurang memahami bagaimana kelanjutan keIslaman Mualaf, mulai persoalan pembinann atau bimbingan agama Islam, pendidikan, dan permasalahan lainnya. Nasrullah sebagai mantan Mualaf (sekarang menjadi Pembina Mualaf di Panti Asuhan al- Falah), mengatakan bahwa:" Persoalan yang saya rasakan dahulu baru masuk Islam adalah ada rasa gamang, bukan karena ragu dengan agama Islam, tetapi bagaimana kelanjutan Islamku kedepannya, permasalahan lain hari demi hari bermunculan seperti kebutuhan pokok, pendidikan dan siapa yang memberikan bimbingan agama Islam selanjutnya, belum lagi ada perasaan terasing dari segi pergaulan dengan orang muslim lain. Saya yakin apa yang saya rasakan dahulu akan dialami oleh Mualaf lain.”

Dari ungkapan Nasrullah, di atas semakin memberi pengetahuan dan pemahaman bahwa menjadi Mualaf itu bukanlah hal yang mudah dilalui sendiri, apalagi bagi usia anakanak, yang masih butuh perhatian, kasih sayang dari orang tua, tetapi karena mereka masuk agama Islam, maka dengan sendirinya harus bepisah dengan keluarga tercinta. Sementara diluar lingkungan keluarganya tidak ada jaminan bahwa dia mendapatkan kasih sayang,

\footnotetext{
${ }^{1}$ Mansoureh Ebrahimi and Kamaruzaman Yusoff, "Islamic Identity, Ethical Principles and Human Values," European Journal of Multidisciplinary Studies 2, no. 6 (2017): 326-37, https://doi.org/10.26417/ejms.v6i1.p325-336.

${ }^{2}$ Lucy Spoliar and Nella van den Brandt, "Documenting Conversion: Framings of Female Converts to Islam in British and Swiss Documentaries," European Journal of Women's Studies XX, no. X (2020): 1-15, https://doi.org/10.1177/1350506820920912.

${ }^{3}$ Sri Hidayati, "Problematika Pembinaan Muallaf Di Kota Singkawang Dan Solusinya," Jurnal Dakwah XV, no. 1 (2014): 111-36, http://ejournal.uin-suka.ac.id/dakwah/jurnaldakwah/article/view/300.
} 
kebutuhannya terpenuhi, dan perlindungan dari diskriminasi dari orang lain. Pendapat lainnya disampaikan oleh Adianto, bahwa: "Diantara permasalahan Mualaf ini adalah sangat kurangnya kepedulian dan pembinaan yang berkesinambungan terutama dalam masalah: akidah, ibadah, pendidikan, ekonomi, sosial, termasuk hubungan mereka dengan keluarga asalnya. permasalahan tersebut tentunya bukanlah persoalan yang mudah bagi Mualaf untuk menghadapinya sendirian, maka dalam hal ini sangat diperlukan kehadiran orang lain, pemerintah, lembaga sosial untuk membantu meringankan beban yang Mualaf hadapi".

Dari pernyataan Adianto di atas, tersirat kekhawatiran terhadap keistikamahan Mualaf dalam keislamannya, apabila tidak terbina dengan baik, maka tidak tertutup kemungkinan Mualaf itu tidak istikamah dengan keislamannya, bahkan dikhawatirkan Mualaf itu murtad atau kembali kepada agama asalnya. Artinya berbagai kemungkinan hal yang pahit bias saja dialami oleh Mualaf kalau tidak mendapat perhatian dan bimbingan dari orang lain atau ada yayasan yang konsen terhadap pembinaan Mualaf, kemungkinan terburuk yang bisa saja terjadi seperti yang di ungkapkan Adianto di atas adalah terjadinya kemurtadan (kembali ke agama awal / agama lain), sebelum masuk Islam. Padahal menurut Mas'oed Abidin dalam bukunya: Islam dalam Pelukan Muhtadin Mentawai, bahwa apabila seseorang telah menerima dan meyakini Islam maka dia harus teguh pendirian (istikamah) agar tidak tidak tercemar ke jurang kehinaan ${ }^{4}$.

Dari pendapat Mas'oed Abidin di atas dapat dipahami bahwa Mualaf yang tidak terbimbing sesuai dengan ajaran agama Islam,maka dapat terjerumus kepada perbuatan tercela dan menjadi orang yang hina di sisi Allah SWT. Oleh sebab itu setiap Mualaf yang sudah harus betul-betul mendapatkan pembinaan, bimbingan sesuai ajaran Islam, baik yang dilakukan secara pribadi, lembaga atau Panti Asuhan yang memiliki kepedulian terhadap pembinaan Mualaf.

Berbicara tentang lembaga atau Panti Asuhan yang memberikan pembinaan atau bimbingan agama Islam kepada Mualaf, maka dalam hal ini Panti Asuhan al-Falah adalah salah satu lembaga sosial yang peduli dan konsisten dalam pembinaan Mualaf di kota Padang. Kepedulian panti asuhan ini dalam pembinaan Mualaf tentu sudah memberikan solusi terhadap permasalahan yang dihadapi Mualaf, walaupun dalam segala keterbatasan. Hal ini sesuai yang disampaikan oleh Pembina sebagai pimpinan Panti asuhan al-Falah bahwa:"Panti asuhan al-Falah berdiri sebagai bentuk keperihatinan dan sekaligus kepedulian terhadap anak-anak Mualaf khususnya yang berasal dari kepulauan mentawai baik mereka yang sudah berada di Padang maupun yang mereka masih di Mentawai, permasalahan anakanak Mualaf ini memang sangat kompleks dan sangat membutuhkan pembinaan yang berkesinambungan baik dari segi pendidikan, bimbingan agamanya, seperti aqidah, ibadah, dan membaca Alquran dengan baik sesuai dengan tuntunan ilmu tajwid. Diharapkan dengan adanya pembinaan ini generasi Mualaf ini dapat memahami ajaran Islam dengan baik dan dapat mengamalkannya dalam kehidupan mereka sehari-hari, kita juga sangat mengharapkan kepada Mualaf untuk istikamah dalam agama Islam sehingga tidak ada nantinya yang kembali kepada ajaran atau agamanya semula."

4 Maskota Delfi, "Islam and Arat Sabulungan in Mentawai," Al-Jami'ah 51, no. 2 (2014): 475-99, https://doi.org/10.14421/ajis.2013.512.475-499. 
Penelitian yang terkait dengan pembinaan Mualaf telah banyak dilakukan oleh para akademisi, misalnya saja Fitriyani dkk yang menegaskan bahwa pendampingan dilakukan dalam bentuk pembelajaran Alquran serta pelaksanaan ibadah salat ${ }^{5}$. Salsabila dan kawankawan juga telah meneliti aspek yang berbeda, yakni program masjid dalam bentuk pembinaan Mualaf, hasil yang ditemukannya ialah bahwa dengan program yang demikian dapat meningkatkan jumlah Mualaf setiap tahunnya ${ }^{6}$. Anuar dan Amri menemukan bahwa dengan menggunakan pendekatan persuasif, pembinaan keagamaan Mualaf dapat dilakukan secara baik, sehingga pengetahuan mereka pada aspek syariah dan akidah dapat meningkat ${ }^{7}$.

Dari pendapat di atas, dapat dipahami bahwa ada harapan yang sangat mendalam dari setiap umat Islam terhadap pembinaan atau bimbingan agama Islam bagi Mualaf secara berkesinambungan, terarah sehingga dapat membantu mualaf untuk mengetahui, memahami dan mengaplikasikan ajaran Islam itu secara kaffah dalam kehidupan sehari-hari, sehingga tidak ada di kemudian hari di antara Mualaf itu yang murtad (kembali kepada agama asalnya). Oleh karenanya, penelitian ini akan mengungkap aspek yang belum diteliti oleh para akademisi, yakni dampak bimbingan keagamaan terhadap sikap beragama Mualaf.

Tempat melakukan penelitian ialah di Panti Asuhan al-Falah yang beralamat di Jalan Parupuk Tabing, N0. 38 RT. 5 RW.11 Kelurahan Parupuk Tabing Kecamatan koto Tangah Kota Padang Sumatera Batera Barat. Jenis penelitian adalah penelitian kualitatif, Sementara itu, untuk menganalisis data penelitian ini,digunakan pendekatan deskriptif, termasuk ekspresi tertulis atau lisan masyarakat dan tindakan yang bisa diamati.

Dalam penelitian ini pengumpulan data yang dilakukan adalah dengan teknik observasi,wawancara dan dokumentasi. Objek yang diobservasi adalah Guru Bimbing Pendidikan Agama Islam Panti Asuhan al-Falah dan Mualaf / anak asuh Panti Asuhan alFalah Kecamatan Koto Tangah Kota Padang, yang diwawancarai ialah Ketua Panti Asuhan al-Falah, Guru Pembimbing agama Islam serta Mualaf yang dibina di Panti Asuhan alFalah. Adapun dokumentasi berupa data Panti Asuhan serta data peserta didik, foto-foto kegiatan maupun foto-foto dokumentasi yang mendukung penelitian.

Analisis data adalah proses pengorganisasian dan pengelompokan data ke dalam pola, kategori, dan deskripsi unit dasar sehingga topik dapat ditemukan dan hipotesis yang layak dapat dirumuskan berdasarkan rekomendasi data. Sehubungan dengan itu, data yang diperoleh melalui observasi dan wawancara dianalisis untuk memastikan bagaimana dampak bimbingan agama Islam terhadap sikap keagamaan Mualaf di Panti Asuhan al- Falah Kecamatan Koto Tangah Kota Padang.

5 Andi Fitriyani et al., "Pendampingan Dan Pembinaan Komunitas Muallaf Melalui Pembibitan Perangkat Syara' Di Desa Wamana Baru Kec. Fena Leisela Kab. Buru, Maluku,” Dialektika 12, no. 1 (2019): 11, https://doi.org/10.33477/dj.v12i1.788.

${ }^{6}$ Miya Salsabila, Arif Rahman, and Asep Iwan Setiawan, "Implementasi Program Pembinaan Mualaf Sebagai Upaya Meningkatkan Pelayanan Masjid," Tadbir: Jurnal Manajemen Dakwah 4, no. 1 (2019): 1-18, https://doi.org/10.15575/tadbir.

${ }^{7}$ Kasiman Anuar and Amsal Amri, "Komunikasi Persuasif Pembinaan Muallaf Oleh Dinas Syari'at Islam Kota Banda Aceh,” Jurnal Ilmiah Mahasiswa FISIP Unsyiah 4, no. 1 (2019): 1-13. 


\section{Hasil dan Pembahasan}

Sesuai dengan data yang ditemukan di panti asuhan Al-Falah diketahui bahwa aspekaspek ajaran Islam yang diberikan pembinaannya kepada Mualaf di panti ialah sebagaimana pada table 1 di bawah ini:

Tabel 1. Aspek Ajaran Islam untuk Pembinaan Mualaf

\begin{tabular}{|l|l|l|}
\hline No & Aspek & Tujuan \\
\hline 1 & Akidah & $\begin{array}{l}\text { Agar Mualaf memiliki keteguhan dan keyakinan yang } \\
\text { kuat terkait kebenaran Islam. }\end{array}$ \\
\hline 2 & Ibadah & $\begin{array}{l}\text { Bimbingan memiliki kemampuan terkait dengan } \\
\text { ibadah sesuai dengan ajaran Islam, mulai dari } \\
\text { berwudhu, salat serta berbagai ibadah lainnya. }\end{array}$ \\
\hline 3 & Membaca Alquran & $\begin{array}{l}\text { Peserta bimbingan memiliki kemampuan membaca } \\
\text { Alquran secara baik dan benar }\end{array}$ \\
\hline 4 & Akhlak & $\begin{array}{l}\text { Mualaf memiliki prilaku yang baik sesuai dengan } \\
\text { ajaran Islam }\end{array}$ \\
\hline
\end{tabular}

Dalam agama Islam, akidah adalah salah satu aspek ajaran Islam yang harus ditanamkan kepada setiap muslim. Akidah adalah hal yang sangat mendasar, karena menyangkut keyakinan yang tidak ada boleh ada keraguan padanya ${ }^{8}$. Akidah itu ialah keyakinan yang nyata yang tidak menerima keraguan dan bantahan ${ }^{9}$, apabila kepercayaan terhadap sesuatu itu masih ada unsur keraguan, maka tidak disebut akidah ${ }^{10}$. Dalam konteks Islam,akidah berarti tali pengikat batin manusia dengan yang diyakininya sebagai Tuhan yang Esa yang patut disembah dan Pencipta serta pengatur alam jagat ini.”

Berdasarkan pendapat di atas maka dalam rangka penanaman kepada setiap muslim perlu adanya bimbingan akidah Islam kepada setiap Mualaf yang sudah menjadi muslim, seperti di panti asuhan al-Falah bahwa salah satu materi bimbingan keagamaan Islam yang diberikan kepada Mualaf di Panti Asuhan al-Falah adalah maslah akidah, hal ini sesuai dengan pernyataan Didianto, sebagai Pembimbing keagamaan mengatakan bahwa: Hal pertama yang harus ditanamkan kepada Mualaf yang dibina di panti asuhan al-Falah adalah masalah akidah Islam, karena hal ini sangat penting sekali diberikan kepada anak asuh yang sebelumnya beragama lain, kita berpikir bahwa tampa mereka mempunyai akidah yang kuat, dan keyakinan yang kuat kepada Allah SWT. Sebagai Tuhan yang kepadanya kita menyembah dan meminta pertolongan, maka mereka tidak akan memahami begitu penting Allah dalam kehidupan. Pemahaman akidah terus diberikan kepada anak asuh Mualaf yang kita bina dengan harapan mereka akan kuat dan timbul rasa fanatiknya terhadap agama Islam yang sudah diyakininya sekarang. Harapan kita juga dengan akidah yang kuat sehingga mereka tidak mudah terpengaruh dengan agama yang dianut sebelumnya."

${ }^{8}$ Rahimah Embong et al., "Islamic Belief and Practices: An Integrative Coping Approach to Life Problems," International Journal of Academic Research in Progressive Education and Development 6, no. 3 (2017): 97109, https://doi.org/10.6007/ijarped/v6-i3/3176.

9 Jonathan Jenkins Ichikawa, "Faith and Epistemology," Episteme 17, no. 1 (2020): 121-40, https://doi.org/10.1017/epi.2018.30.

${ }^{10}$ James H. Leuba, "A Study in the Psychology of Religious Phenomena," The American Journal of Psychology 7, no. 3 (1986): 309-85, https://doi.org/https://www.jstor.org/stable/1411387. 
Bimbingan Ibadah bagi Mualaf di Panti Asuhan al-Falah. Salat dalam Islam mempunyai kedudukan yang sangat penting untuk dilaksanakan dalam kehidupan seharihari. Salat juga merupakan salah satu tanda adanya hidayah dan keimanan ${ }^{11}$, karena sholat sebagai tiang agama. Agar seseorang dapat melaksanakan salat dengan baik dan benar, maka perlu adanya ilmu, pemahaman dan bimbingan yang benar sesuai dengan tuntunan salat, kaitannya dengan pelaksanaan bimbingan sholat di Panti Asuhan, hal ini dapat diketahui sesuai dengan hasil wawancara penulis dengan Didianto, bahwa: " dalam mengajarkan atau memberikan bimbingan ibadah salat kepada Mualaf yang kita bina di Panti Aasuhan alFalah, yang pertama yang harus dipahamkan kepada mereka bahwa salat merupakan ibadah yang mulia disisi Allah, melalui ibadah salat manusia akan lebih dekat dengan khaliknya, melalui ibadah salat pula Allah akan memberikan rahmat dan pertolongannya kepada manusia. Kedua diajarkan kepada Mualaf bacaan salat dengan perlahan-lahan sampai mereka fasih, ketiga memperaktekkan bacaan salat sesuai dengan gerakannya, dalam mempraktekkan salat ini biasanya dimulai dari sendiri-sendiri dan secara bersamasama.harapan kita dengan adanya bimbingan salat ini Mualaf sudah mampu melaksanakan salat baik sendiri maupun berjamaah. Harapan saya juga kepada Mualaf yang sudah bisa melaksanakan salat agar tidak meninggalkannya atau melalaikannya,sehingga nanti salat itu menjadi kebutuhan religius dalam kehidupan mereka".

Alquran sebagai pedoman bagi umat manusia, tentu harus dipelajari dengan cara belajar membaca, memahami makna yang terkandung dalam Alquran sehingga dapat menambah keyakinan dan menjadikan Alquran sebagai petunjuk dalam berperilaku dalam kehidupan sehari-hari1 ${ }^{12}{ }^{13}$. Berdasarkan hasil wawancara penulis dengan Nasrullah bahwa sebagai salah seorang tenaga pembimbing membaca Alquran "Dalam melaksanakan bimbingan membaca Alquran, ini kita lakukan setiap hari alhamdulillah mereka sudah 90 persen sudah bisa membaca Alquran walaupun belum semuanya sangat fasih. Dalam pelaksanaan bimbingan Alquran para Mualaf dikelompokkan berdasarkan tingkat kemahiran mereka membaca yang dibimbing oleh Mualaf yang lebih fasih dalam membaca Alquran dan di akhir waktu mereka akan dievaluasi kembali oleh Ustaz/Ustazah yang bertugas dalam dalam membimbing Alquran pada waktu itu. Selanjutnya bagi Mualaf yang sudah fasih dan mahir membaca Alquran akan dibimbing untuk tahfiz atau menghafal Alquran. Tujuan bimbingan Alquran ini diadakan agar setiap Mualaf dapat membaca Alquran dengan dengan baik dan benar sesuai dengan ilmu tajwid", pernyataan ini selaras dengan kesimpulan Nurlaili dan kawan-kawan yang menegaskan bahwa pembelajaran Alquran merupakan keharusan bagi setiap muslim ${ }^{14}$.

${ }^{11}$ Nizamul Iswari, Mursal, and Rahmi, "Pembelajaran Shalat Dalam Mata Pelajaran Praktik Ibadah Di SMK Muhammadiyah 1 Padang," Rubama: Islamic Education Journal 3, no. 1 (2020): 34-44, https://jurnal.umsb.ac.id/index.php/ruhama/article/view/1948/1615.

12 Aguswan Rasyid et al., "What AL-Quran Say About 'Aql," European Journal of Molecular and Clinical Medicine 7, no. 11 (2020): 228-34.

${ }^{13}$ Nur Alim, Mahyudin Ritonga, and Mafardi Mafardi, "Korelasi Kegiatan Ekstrakurikuler Sanggar AlQuran Dengan Hasil Belajar Al-Quran Hadits Di MAN 4 Pasaman Barat," Intiqad: Jurnal Agama Dan Pendidikan Islam 12, no. 2 (2020): 246-55, https://doi.org/10.30596/intiqad.v12i2.4640.

${ }^{14}$ Nurlaili, Mahyudin Ritonga, and Mursal, "Muroja'ah Sebagai Metode Menghafal Al Quran Studi Pada Rumah Tahfiz Yayasan Ar-Rahmah Nanggalo Padang,” Menara Ilmu XIV, no. 02 (2020): 1-5. 
Pendapat lain disampaikan oleh Zainal Kelana, sebagai pembimbing membaca Alquran di Panti Asuhan al-Falah bahwa: Membaca Alquran bagi Mualaf tentu hal yang harus betulbetul diajarkan dengan baik, karena mereka pada umumnya belum pernah mengenal Alquran, berbeda tentunya dengan anak yang berada dalam lingkungan atau keluarga yang sudah muslim. Bagi Mualaf mempelajari Alquan tentu suatu hal yang baru dan menyulitkan pada awalnya, namun karena kesabaran dan kesungguh-sungguhan pembimbing dan anak asuh sehingga pada akhirnya mereka dapat membaca Alquran dengan baik.

Islam sebagai agama yang mulia yang diturunkan oleh Allah SWT. Untuk mengatur kehidupan manusia dengan Khalik, hubungan manusia dengan manusia lainnya, hubungan manusia dengan alam semesta. Akhlak yang mulia itu tentu harus ditanamkan kepada setiap orang agar menjadi perilaku dalam kehidupan sehari-hari. Menurut Ustazul di Panti Asuhan al-Falah bahwa: Bimbingan akhlak ini salah satu yang menjadi prioritas juga dilaksanakan, karena menurutnya Islam itu akan terlihat dalam perilaku seseorang yang telah beragama Islam. Mualaf yang kita bina di Panti Asuhan al-Falah selalu kita tanamkan agar berakhlak yang mulia, baik dalam ucapan, perbuatan. Mereka juga harus mengetahui dan melaksanakan akhlak yang mulia terhadap orang lain, termasuk kepada keluarganya walaupun berbeda keyakinan."

Sementara ustaz Nasrullah, mengatakan bahwa "Bimbingan akhlak salah satu komitmen kami sebagai tenaga pembimbing di Panti Asuhan al-Falah untuk membimbing anak asuh (Mualaf) agar berakhlak mulia. Diantara akhlak yang diajarkan adalah: akhlak kepada Allah, nabi dan rasul, akhlak kepada orang tua, guru, teman, termasuk kepada masyarakat, terutama lingkungan Panti Asuhan al-Falah. Pemberian materi akhlak ini biasanya setiap selesai salat magrib atau subuh, mereka terus kita perhatikan sehari-hari bagaimana penerapan akhlak yang baik itu, metode yang lebih tepat menurut saya dalam menanamkan akhlak ini adalah dengan keteladanan dari guru pembimbing, pengurus panti asuhan al-Falah, bahkan dari masyarakat lingkungan Panti Asuhan al-Falah”.

Dalam melaksanakan suatu kegiatan tentu tidak terlepas dari adanya faktor yang mendukung dan menghambat, semakin besar faktor yang mendukung terhadap pekerjaan itu, maka keberhasilan akan lebih mudah terwujud sesuai dengan harapan atau tujuan yang sudah ditetapkan. Sebaliknya apabila faktor kendala yang lebih dominan mempengaruhi kegiatan tersebut, maka akan menyulitkan untuk meraih hasil yang diinginkan.

Faktor pendukung yang penulis maksud dalam penelitian adalah segala sesuatu yang memberikan manfaat untuk kemajuan dan perkembangan panti asuhan al- Falah, baik berbentuk materi maupun non materi, seperti pemikiran yang positif (yang membangun), terkhusus yang ada kaitannya dengan proses pelaksanaan bimbingan agama Islam bagi Mualaf di Panti Asuhan, bimbingan agama yang penulis maksud adalah: Bimbingan akidah Islam, Bimbingan Salat, Bimbingan Alquran dan bimbingan akhlak. Sehingga penulis mengetahui betul faktor-faktor apa saja yang dapat mempengaruhi bimbingan agama Islam di Panti Asuhan terlaksana dengan baik. Menurut Ustazul sebagai ketua Panti Asuhan alFalah mengatakan bahwa: Adapun faktor pendukung dalam melaksanakan bimbingan agama Islam kepada Mualaf atau anak asuh di Panti Asuhan al-Falah adalah: a. Fasilitas asrama Panti yang sudah memadai, karena Panti Asuhan al-Falah ada dua asrama, yaitu asrama untuk laki-laki dan asrama untuk perempuan, b. Kepengurusan panti yang masih solid untuk bekerjasama dan sama-sama bekerja c. Tenaga pembimbing agama Islam yang relatif memadai sesuai dengan jumlah anak asuh, d. Adanya perhatian dari instansi 
pemerintah, swasta maupun dari para dermawan, e. Jumlah anak asuh yang masih standar dengan fasilitas Panti Asuhan al-Falah. Dari pernyataan Ustazul di atas sebagai ketua Panti asuhan al-Falah, sesuai dengan hasil observasi penulis bahwa Panti Asuhan al-Falah sudah mempunyai dua gedung asrama, satu asrama untuk laki-laki dan satu lagi asrama untuk perempuan.

Pernyataan ketua panti asuhan al-Falah di atas sesuai dengan hasil observasi penulis, bahwa ada dua asrama yang ada di Panti asuhan al-Falah yang terpisah satu asrama untuk putri yang satu lagi untuk putra, dari hasil pemantauan penulis bahwa kedua asrama dibangun secara permanen dan asrama putra direncanakan pembangunan lantai dua.

Dalam kaitannya dengan faktor penghambat ini peneliti ingin mendapat infomasi yang akurat sehingga diketahui faktor-faktor apa saja yang dihadapi pengurus panti asuhan alFalah dalam mengurus atau melaksanakan berbagai macam kegiatan Mualaf, terkhusus dalam memberikan bimbingan agama Islama di Panti Asuhan al-Falah. Untuk mendapatkan informasi tentang kendala-kendala yang dihadapi pengurus panti asuhan alFalah, maka yang pertama yang peneliti wawancarai adalah Ustazul sebagai ketua Panti Asuhan al-Falah, menurutnya yang menjadi hambatan bagi pengurus dalam melaksanakan berbagai kegiatan di Panti Asuhan al-Falah adalah:

1. Masih kurang donatur tetap untuk pembiayaan aktifitas di panti asuhan al-Falah.

2. Biaya kebutuhan yang terus bertambah sesuai dengan pertumbuhan dan perkembangan anak asuh di Panti Asuhan al-Falah.

3. Kurangnya yayasan atau Panti Asuhan yang bergerak dalam pembinaan Mualaf di kota Padang khususnya sebagai wadah bagi yayasan untuk bertukar pikiran dalam memajukan panti asuhan ke depan.”

Mualaf sebagai seorang yang baru masuk Islam tentu sangat perlu mendapatkan perhatian dan bimbingan agama Islam yang berkesinambungan. Bimbingan agama Islam sebenarnya menjadi kebutuhan spiritual bagi Mualaf, dengan adanya bimbingan agama Islam dalam berbagai aspeknya diharapkan dapat menambah ilmu, pemahaman Mualaf terhadap Islam yang kafah $^{15}$, karena agama Islam akan lebih baik dan terarah dengan seorang guru yang mampu memberikan pemahaman kepada Mualaf. Dalam memberikan bimbingan agama Islam kepada Mualaf akan lebih baik dilakukan secara bersama, walaupun secara individu memungkinkan untuk dilaksanakan.

Panti asuhan al-Falah adalah sebuah wadah yang khusus membantu Mualaf dan berusaha melaksanakan bimbingan agama Islam terhadap Mualaf, hal ini merupakan bagian dari tanggung jawab panti asuhan untuk memberikan bimbingan, mengajak umat ke dalam kebaikan. Setelah peneliti mendapatkan dan memaparkan hasil data-data yang berkaitan dengan penelitian sesuai dengan rumusan dan tujuan penelian, maka di bawah ini akan peneliti bahas tentang temuan-temuan tersebut baik data yang bersumber dari observasi, wawancara dan dokumentasi yang peneliti dapat selama mengadakan penelitian di Panti Asuhan al-Falah, aspek penelitian yang penulis maksud sebagai berikut:

15 Anton Widodo, "Urgensi Bimbingan Keagamaan Islam Terhadap Pembentukan Keimanan Mualaf," Jurnal Bimbingan Penyuluhan Islam 1, no. 01 (2019): 65-90, https://doi.org/10.32332/jbpi.v1i01.1476. 
Pertama, bimbingan akidah kepada Mualaf di Panti Asuhan al-Falah Kecamatan Koto Tangah Kota Padang dan pengaruhnya terhadap perilaku keberagamaan Mualaf. Akidah dalam Islam adalah hal yang sangat mendasar dan wajib ada pada diri sesorang, kalau sudah mengaku masuk Islam, akidah secara materi tidak diketahui bentuk wujudnya namun memberikan pengaruh yang besar terhadap perilaku manusia ${ }^{16}{ }_{-}^{17}$. Selain itu, akidah juga diartikan komitmen spiritual terhadap Allah dengan segala kemahaannya-Nya. Ikatan atau komitmen dengan Allah terikat dengan kuat, tangguh, rapat, tidak longgar dan renggang, sehingga kekuatannya diyakini tidak mudah tanggal betapapun kuatnya angin tipu daya dan rayuan penganut kesesatan." Dari pendapat di atas memberikan penjelasan dan penekanan tentang pentingnya akidah Islam, tumbuh dan berkembangnya akidah dalam diri seseorang dengan kuat, kokoh, sehingga tidak mudah rusak, terpengaruh dari setiap rayuan, godaan, gangguan dari setiap usaha setan yang ingin mengganggu akidah seseorang itu menjadi lemah atau hilang dari jiwa setiap manusia yang mengaku orang yang bertauhid kepada Allah SWT.

Kedua, Bimbingan Sholat kepada Mualaf di Panti Asuhan al-Falah Kecamatan Koto Tangah Kota Padang. Apabila seorang muslim telah mempunyai akidah dengan mentauhidkan Allah dengan penuh keyakinan dalam hatinya, maka dia wajib baginya untuk mendirikan salat fardu lima waktu sehari semalam. Di panti asuhan al-Falah telah melaksanakan bimbingan sholat kepada Mualaf, hal ini sesuai dengan hasil wawancara penulis dengan 5 tenaga pembimbing agama Islam yang ada di Panti Asuhan al-Falah dan wawancara dengan mullaf yang dibimbing dalam panti tersebut.

Dari hasil wawancara dengan tenaga pembimbing agama Islam di Panti Asuhan alFalah maka dapat diketahui bahwa bimbingan salat itu sangat dibutuhkan oleh Mualaf, karena pada umumnya mereka belum dapat melaksanakanya sendirian, maka disinilah fungsi seorang guru untuk membimbing Mualaf ini sampai mereka dapat melaksanakan salat sesuai dengan ilmunya. Hal ini sesuai dengan hasil wawancara dengan Mualaf yang mendapat bimbingan salat di panti asuhan al-Falah bahwa sebelum mendapatkan bimbingan salat dari tenaga pembimbing,kami belum dapat melaksanakan salat dengan baik dan benar,namun setelah kami mengikuti bimbingan salat secara terus-menerus maka kami sudah dapat melaksanakannya baik secara sendiri-sendiri dan berjama'ah.

Dengan adanya bimbingan salat ini, maka memberikan dampak yang positif kepada Mualaf, pengaruh positif yang dimaksud adalah: pertama Mualaf sudah dapat melaksanakan salat sesuai dengan tuntunan salat yang baik dan benar, kedua Mualaf sudah terbiasa melaksanakan salat berjama'ah setiap harinya di panti asuhan al-Falah, ketiga Mualaf terbiasa disiplin dalam melaksanakan sholat sesuai dengan waktu masuk salat,keempat Mualaf termotivasi melaksanakan sholat sunah seperti salat rawatib dan ghairu rawatib,kelima Mualaf terbiasa bangun tidur lebih awal dan lebih disiplin dalam melaksanakan kegiatan yang ada di Panti Asuhan al-Falah.

Ketiga, Bimbingan membaca Alquran untuk Mualaf di Panti Asuhan al-Falah Kecamatan Koto Tangah Kota Padang. Alquran sebagai salah satu sumber ajaran Islam menjadi kewajiban bagi setiap muslim untuk mempelajarinya, seperti belajar membaca, memahami makna yang terkandung di dalamnya dan mengaplikasikan dalam kehidupan

16 Paul O'Callaghan, "Cultural Challenges to Faith: A Reflection on the Dynamics of Modernity," Church, Communication and Culture 2, no. 1 (2017): 25-40, https://doi.org/10.1080/23753234.2017.1287281.

${ }^{17}$ Linda J. Skitka et al., "Moral and Religious Convictions: Are They the Same or Different Things?," PLoS ONE 13, no. 6 (2018), https://doi.org/10.1371/journal.pone.0199311. 
sehari-hari. Untuk belajar Alquran, maka dibutuhkan peran seorang guru atau pembimbing yang mumpuni untuk membangkitkan semangat Mualaf dalam belajar membaca Alquran. Sesuai dengan hasil wawancara penulis dengan tenaga pembimbing belajar Alquran di panti asuhan al-Falah bahwa Mualaf sudah mendapat bimbingan dalam membaca Alquran setiap hari selesai salat ashar. Mualaf yang sudah diwawancarai juga mengatakan bahwa mereka selalu mendapat bimbingan Alquran dari guru pembimbing di panti asuhan al-Falah selesai sholat ashar. Dampak dari adanya bimbingan belajar Alquran terhadap Mualaf, maka dapat dikemukakan bahwa; dengan adanya bimbingan belajar Alquran pada umumnya Mualaf di Panti Asuhan al-Falah sudah dapat membaca Alquran walaupun masih butuh bimbingan secara terus menerus.dengan adanya bimbingan belajar Alquran Mualaf sudah bias menghafal ayat-ayat Alquran, mempelajari makna yang tekandung dalam Alquran. Dengan demikian dapat disimpulkan bahwa bimbimngan belajar Alquran bagi Mualaf harus terus dilaksanakan agar mereka terbiasa dalam mebaca Alquran bertambah mahir.

Keempat, bimbingan akhlak kepada Mualaf di Panti Asuhan al-Falah dan dampaknya terhadap perilaku keberagamaan Mualaf. Akhlak adalah salah satu aspek yang sentral dalam Islam, karena hal ini berkaitan dengan perbuatan, tingkah laku yang mengaplikasikan ajaran Islam dalam kehidupan nyata. Nilai-nilai kemulian dan keagungan Islam akan dapat terealisasi melalui perilaku sorang muslim dalam kehidupan sehari-hari. Akhlak merupakan ajaran pokok dalam Islam ${ }^{18}$ dan nabi Muhammad secara khusus diutus membawa misi untuk menyempurnakan akhlak manusia dengan memberikan keteladanan dalam berperilaku". Untuk mengaplikasikan ajaran Islam dalam kehidupan sangat dibutuhkan keteladan dan bimbingan dari orang yang lebih mulia perilakunya ${ }^{19}{ }_{-}^{20}$. Di panti asuhan alFalah proses pembinaan akhlak ini terus berlajan, hal ini sesuai dengan observasi dan hasil wawancara penulis dengan guru pembimbing akhlak, bahwa bimbingan akhlak kepada Mualaf akan terus dilaksanakan supaya mereka merasakan akan kemuliaan Islam itu yang belum pernah mereka rasakan selama ini dalam ajaran agama sebelumya, dari hasil wawancara penulis dengan Mualaf yang mendapat bimbingan akhlak di Panti Asuhan alFalah mengatakan bahwa mereka selalu mendapat perhatian, bimbingan dari guru pembimbing agar selalu menjaga akhlak mulia baik dalam lingkungan panti asuhan al-Falah maupun diluar lingkungan panti asuhan.

\section{Penutup}

Berdasarkan hasil penelitian serta analisisnya dapat disimpulkan bahwa: Bimbingan akidah bagi Mualaf sangat penting diberikan untuk memperkuat dan menjaga keistikamahan mereka dalam Islam. Bimbingan salat bagi Mualaf di Panti Asuhan al-Falah bertujuan agar setiap Mualaf dapat melaksanakan salat dengan baik, adapun dampak dari bimbingan salat ini para Mualaf yang sebelumnya belum bisa melaksanakan salat setelah adanya bimbingan, mereka mampu melaksanakan salat dan termotivasi melaksanakan salat sunah dan dapat menambah disiplin mereka terutama bangun tidur. Bimbingan membaca

18 Terence Lovat, "Islamic Morality: Teaching to Balance the Record," Journal of Moral Education 45, no. 1 (January 2, 2016): 1-15, https://doi.org/10.1080/03057240.2015.1136601.

${ }_{19}$ Abdul Hakim Abdullah and Kabara Auwal Halabi, "The Wisdom: A Concept of Character Building Based on Islamic View," International Journal of Academic Research in Business and Social Sciences 7, no. 5 (2017): 412-25, https://doi.org/10.6007/ijarbss/v7-i5/2979.

${ }^{20}$ Rizka Widayanti, Suci Ramadhanti Febriani, and Mahyudin Ritonga, "ICBC Program to Forming Character Building," Jour of Adv Research in Dynamical \& Control Systems 12, no. 02 (2020): 3265-73, https://doi.org/10.5373/JARDCS/V12I2/S20201448. 
Alquran bagi Mualaf, tujuannya adalah agar setiap Mualaf mampu membaca Alquran sesuai dengan ilmu tajwid yang baik dan benar, adapun dampak dari bimbingan membaca Alquran bagi Mualaf adalah Mualaf sudah mampu membaca Alquran dengan baik dan dapat termotivasi mereka membaca Alquran atas dasar keinginan sendiri.

\section{Bibliografi}

Abdullah, Abdul Hakim, and Kabara Auwal Halabi. "The Wisdom: A Concept of Character Building Based on Islamic View." International Journal of Academic Research in Business and Social Sciences 7, no. 5 (2017): 412-25. https://doi.org/10.6007/ijarbss/v7-i5/2979.

Alim, Nur, Mahyudin Ritonga, and Mafardi Mafardi. "Korelasi Kegiatan Ekstrakurikuler Sanggar Alquran Dengan Hasil Belajar Alquran Hadits Di MAN 4 Pasaman Barat." Intiqad: Jurnal Agama Dan Pendidikan Islam 12, no. 2 (2020): 246-55. https://doi.org/10.30596/intiqad.v12i2.4640.

Anuar, Kasiman, and Amsal Amri. "Komunikasi Persuasif Pembinaan Mualaf Oleh Dinas Syari'at Islam Kota Banda Aceh.” Jurnal Ilmiah Mahasiswa FISIP Unsyiah 4, no. 1 (2019): 1-13.

Delfi, Maskota. "Islam and Arat Sabulungan in Mentawai." Al-Jami'ah 51, no. 2 (2014): 475-99. https://doi.org/10.14421/ajis.2013.512.475-499.

Ebrahimi, Mansoureh, and Kamaruzaman Yusoff. "Islamic Identity, Ethical Principles and Human Values." European Journal of Multidisciplinary Studies 2, no. 6 (2017): 326-37. https://doi.org/10.26417/ejms.v6i1.p325-336.

Embong, Rahimah, Sakinah Salleh, Wan Mazwati Wan Yusof, Normila Noruddin, Muhamad Zaid Bin Ismail, Mariam Nabilah Mohd Noor, and Nur Anis Abdullah. "Islamic Belief and Practices: An Integrative Coping Approach to Life Problems." International Journal of Academic Research in Progressive Education and Development 6, no. 3 (2017): 97-109. https://doi.org/10.6007/ijarped/v6-i3/3176.

Fitriyani, Andi, Baiti Renel, Darma, and Subair. "Pendampingan Dan Pembinaan Komunitas Mualaf Melalui Pembibitan Perangkat Syara' Di Desa Wamana Baru Kec. Fena Leisela Kab. Buru, Maluku." Dialektika 12, no. 1 (2019): 11. https://doi.org/10.33477/dj.v12i1.788.

Hidayati, Sri. "Problematika Pembinaan Mualaf Di Kota Singkawang Dan Solusinya." Jurnal Dakwah XV, no. 1 (2014): 111-36. http://ejournal.uinsuka.ac.id/dakwah/jurnaldakwah/article/view/300.

Ichikawa, Jonathan Jenkins. "Faith and Epistemology." Episteme 17, no. 1 (2020): 121-40. https://doi.org/10.1017/epi.2018.30.

Iswari, Nizamul, Mursal, and Rahmi. "Pembelajaran Salat Dalam Mata Pelajaran Praktik Ibadah Di SMK Muhammadiyah 1 Padang." Ruhama :Islamic Education Journal 3, no. 1 (2020): 34-44. https:// jurnal.umsb.ac.id/index.php/ruhama/article/view/1948/1615.

Leuba, James H. "A Study in the Psychology of Religious Phenomena." The American Journal of Psychology 7, no. 3 (1986): 309-85. https://doi.org/https://www.jstor.org/stable/1411387. 
Lovat, Terence. "Islamic Morality: Teaching to Balance the Record." Journal of Moral Education 45, no. 1 (January 2, 2016): 1-15. https://doi.org/10.1080/03057240.2015.1136601.

Nurlaili, Mahyudin Ritonga, and Mursal. "Muroja'ah Sebagai Metode Menghafal Al Quran Studi Pada Rumah Tahfiz Yayasan Ar-Rahmah Nanggalo Padang." Menara Ilmu XIV, no. 02 (2020): 1-5.

O'Callaghan, Paul. "Cultural Challenges to Faith: A Reflection on the Dynamics of Modernity." Church, Communication and Culture 2, no. 1 (2017): 25-40. https://doi.org/10.1080/23753234.2017.1287281.

Rasyid, Aguswan, Mahyudin Ritonga, Ahmad Lahmi, Talqis Nurdianto, Raja Ritonga, and Supardi Ritonga. "What Alquran Say About 'Aql." European Journal of Molecular and Clinical Medicine 7, no. 11 (2020): 228-34.

Salsabila, Miya, Arif Rahman, and Asep Iwan Setiawan. "Implementasi Program Pembinaan Mualaf Sebagai Upaya Meningkatkan Pelayanan Masjid." Tadbir: Jurnal Manajemen Dakwah 4, no. 1 (2019): 1-18. https://doi.org/10.15575/tadbir.

Skitka, Linda J., Brittany E. Hanson, Anthony N. Washburn, and Allison B. Mueller. "Moral and Religious Convictions: Are They the Same or Different Things?" PLoS ONE 13, no. 6 (2018). https://doi.org/10.1371/journal.pone.0199311.

Spoliar, Lucy, and Nella van den Brandt. "Documenting Conversion: Framings of Female Converts to Islam in British and Swiss Documentaries." European Journal of Women's Studies XX, no. X (2020): 1-15. https://doi.org/10.1177/1350506820920912.

Widayanti, Rizka, Suci Ramadhanti Febriani, and Mahyudin Ritonga. "ICBC Program to Forming Character Building." Jour of Adv Research in Dynamical \& Control Systems 12, no. 02 (2020): 3265-73. https://doi.org/10.5373/JARDCS/V12I2/S20201448.

Widodo, Anton. "Urgensi Bimbingan Keagamaan Islam Terhadap Pembentukan Keimanan Mualaf." Jurnal Bimbingan Penyuluban Islam 1, no. 01 (2019): 65-90. https://doi.org/10.32332/jbpi.v1i01.1476. 